$\begin{array}{ll}\text { Abstracta Iranica } & \begin{array}{l}\text { Abstracta Iranica } \\ \text { Revue bibliographique pour le domaine irano-aryen }\end{array} \\ & \text { Volume } \mathbf{3 7 - 3 8 - 3 9} \text { | } 2018 \\ \text { Comptes rendus des publications de 2014-2016 }\end{array}$

\title{
Eric Morvillez (éd.). Paradeisos. Genèse et métamorphose de la notion de paradis dans l'Antiquité
}

\section{Astrid Nunn}

\section{(2) OpenEdition}

Journals

Édition électronique

URL : http://journals.openedition.org/abstractairanica/42596

DOI : 10.4000/abstractairanica.42596

ISBN : 1961-960X

ISSN : 1961-960X

Éditeur :

CNRS (UMR 7528 Mondes iraniens et indiens), Éditions de l'IFRI

\section{Référence électronique}

Astrid Nunn, «Eric Morvillez (éd.). Paradeisos. Genèse et métamorphose de la notion de paradis dans I'Antiquité », Abstracta Iranica [En ligne], Volume 37-38-39 | 2018, document 11, mis en ligne le 10 mars 2018, consulté le 28 septembre 2020. URL : http://journals.openedition.org/abstractairanica/42596 ; DOI : https://doi.org/10.4000/abstractairanica.42596

Ce document a été généré automatiquement le 28 septembre 2020

Tous droits réservés 


\title{
Eric Morvillez (éd.). Paradeisos. Genèse et métamorphose de la notion de paradis dans l'Antiquité
}

\author{
Astrid Nunn
}

\section{RÉFÉRENCE}

Eric Morvillez (éd.). Paradeisos. Genèse et métamorphose de la notion de paradis dans l'Antiquité (Orient et Méditerranée-Archéologie 15), Paris, de Boccard, 2014, 348 p., ill.

1 Ce volume est le résultat d'un congrès qui a eu lieu à Avignon en 2009. Diverses disciplines de l'histoire, de l'archéologie et de la lexicologie se sont penchées sur la notion de "paradis» dans l'Antiquité. Deux contributions concernent l'époque achéménide, celles de Clarisse Herrenschmidt (Le paradis perse " tout bonheur ») et de Christophe Benech et Rémy Boucharlat (Organisation spatiale du parc de Pasargades). Ils font l'objet d'une recension à part dans ce volume d'Abstracta Iranica.

\section{AUTEURS}

\section{ASTRID NUNN}

Université de Munich 